\section{Production Potential of Four Winter Annual Grasses}

\section{W. C. ROBOCKER}

Highlight: Forage production of downy brome, rattlesnake chess, Japanese brome, and medusahead were compared in a nursery trial on an individual plant basis. Downy brome and Japanese brome produced significantly more forage than did rattlesnake chess or medusahead. The difference in production adds justification for selective control of medusahead in downy brome with diuron.

Downy brome (Bromus tectorum $\mathrm{L}$ ) is of primary importance in the western United States, where it dominates millions of acres in the northern Great Basin and the Columbia Basin. Many investigators have noted the value of downy brome as a palatable forage which is extensively relied upon for early spring or spring-fall grazing, but because of fluctuations in precipitation, grazing capacity also varies widely (Murray, 1970).

Daubenmire (1970) describes downy brome as being pre-adapted to the steppe environment of Washington and the most inherently adaptable plant to take possession of herb-dominated uplands when they are grazed excessively or when abandoned after cultivation. In the most arid part of the steppe region, downy brome is the only one of the annual bromes to become established in these communities. In the less arid parts of the Washington steppe, downy brome competes with other introduced annual bromes, principally Japanese brome ( $B$. japonicus Thunb.), soft chess (B. mollis L.), and rattlesnake chess $(B$. brizaeformis Fisch. \& Mey.), but only in small, local areas have any of these latter species achieved some degree of dominance.

Large areas once dominated by downy brome and other annuals now have been invaded by medusahead (Taeniatherum asperum [Sim.] Nevski), a winter annual grass of increasing importance. Establishment of medusahead has been considered a step downward from the standpoint of graziers because of its high silica content, low palatability, rapid build-up of organic matter, competitiveness, and low productivity.

On the premise that downy brome, medusahead, and other annual bromes will continue to occupy areas that are not physically or economically suited to renovation or reseeding, a nursery study was

The author is research agronomist at the Plant Science Research Division, Agricultural Research Service, U. S. Department of Agriculture, Washington State University, Pullman.

The Plant Science Research Division, Agr. Res. Serv., U. S. Dep. Agr., and the Washington Agricultural Experiment Station cooperated in investigation to produce the information paper. Manuscript received April 28, 1972. made on comparative production of downy brome, rattlesnake chess, Japanese brome, and medusahead at Pullman, Wash. Since 3-(3,4-dichlorophenyl)-1, 1-dimethylurea (diuron) has been shown to selectively control medusahead in downy bromè 1 (Young and Evans, 1972), data on four species are presented to indicate comparative production on a plant-for-plant basis in favorable growing conditions and to point up the desirability of considering selective control among annual grasses in range management.

\section{Materials and Methods}

A preliminary greenhouse trial in the winter of 1960-1961, in which dry top growth of downy brome, rattlesnake chess, and medusahead was compared on an individual plant basis, indicated no significant difference between downy brome and rattlesnake chess, but significantly less production from medusahead than from the other two species.

In autumn 1961, approximately 200 seeds of downy brome, medusahead, and rattlesnake chess, with awns of the first two species removed, were planted in four replicates in a $3-\mathrm{m}$ rows, with $76 \mathrm{~cm}$ between rows, in the Washington State University weed nursery at Pullman. The soil was a Palouse silt loam. No fertilizer was added. In autumn of 1962,1963 , and 1964 , the same species were planted with Japanese brome also included in the tests. Date of emergence of seed heads of each species was noted, and top growth was harvested 4 to 5 weeks after head emergence of each species.

To compare individual plant production, 10 plants beginning with the 10th plant from one end of the species row and every 10 th plant to the 100 th plant, were harvested for yield of top growth. All samples were air dried on greenhouse benches and weighed for dry matter production. Material from the 1964 planting was lost to livestock before harvest in 1965. Production data were subjected to analysis of variance and means compared with Duncan's multiple range test.

\section{Results and Discussion}

Yields of 10-plant samples (Table 1) indicated that on a plant-for-plant basis there was no significant difference between downy brome and Japanese brome. Both species yielded significantly more than medusahead. Kattlesnake chess yielded significantly less than the other two bromes in the 1963-1964, 2-year average. No significant difference in production of rattlesnake chess and medusahead was found. Comparison of yields of the three species grown in 1962 vs. 1963

\footnotetext{
${ }^{1}$ Robocker, W. C. Where research is leading us. Paper presented to Pacific Northwest Section, Am. Soc. Range Manage., Wenatchee, Wash., Nov. 16, 1964.
} 
Table 1. Forage yield ${ }^{1}$ (g, air dry) of 10-plant
samples of four species of winter annual grasses in a 3-year period.

\begin{tabular}{lclll}
\hline \hline Species & 1962 & 1963 & 1964 & $\mathrm{Avg}^{2}$ \\
\hline Downy brome & $66 a$ & $62 a$ & $76 a b$ & $69 a b$ \\
Japanese brome & - & $59 a b$ & $95 a$ & $77 a$ \\
Rattlesnake chess & $47 b$ & $36 b c$ & $62 b c$ & $49 c$ \\
Medusahead & $45 b$ & $32 c$ & $44 c$ & $38 c$ \\
Average & $53^{3}$ & 49 & $69^{4}$ & - \\
\hline
\end{tabular}

1 Average of four replications. Numbers in the same column not followed by the same letter 2 are significantly different at the $5 \%$ level.

2 Averages and combined analysis are on 1963 and 1964 data.

3 Average yield of three species common to 1962 and 1963 not significantly different.

${ }^{4}$ Average yield of 1964 significantly greater than in 1963 at the $1 \%$ level.

showed no significant difference in the yearly averages. The average yield of the four species in 1964 was significantly greater in 1963 at the $1 \%$ level.

The total amount of precipitation from September through June (1961-1962, 1962-1963, 1963-1964) was 52.4, 52.4, and $53.2 \mathrm{~cm}$, respectively. The greater yield of top growth in 1964 as compared with 1963 cannot be explained on the basis of precipitation alone.

Downy brome and Japanese brome were similar in phenology as well as in yield. There was a difference of about a week's lag in emergence of seed heads of Japancse brome, while heads of rattlesnake chess emerged about 2 weeks and those of medusahead up to 3 weeks later than downy brome. The additional time required for development of medusahead, when soil moisture is being depleted by competitive, earlier maturing species, tends to further limit its inherently low vegetative production.

Rattlesnake chess appeared to be of particular interest because its lack of awns enhances its value as a forage plant in the mature stage of growth. However, it does not appear to have a high yield potential.

\section{Literature Cited}

Daubenmire, R. 1970. Steppe vegetation in Washington. Wash. Agr. Exp. Sta. Tech. Bull. 62. $131 \mathrm{p}$.

Murray, Robert B. 1971. Grazing capacity, sheep gains: Cheatgrass, bunchgrass ranges in southern Idaho. J. Range Manage. $24: 407-410$.

Young, James A., and Raymond A. Evans. 1972. Conversion of medusahead to downy brome communities with diuron. J. Range Manage. 25:40-43.

\section{回回 回}

